\title{
BIODIVERSIDADE E DISTRIBUIÇÃO ESPAÇO-TEMPORAL DA DENSIDADE LARVAL DE ANOMURA, AXIIDEA E GEBIIDEA (CRUSTACEA, DECAPODA) EM UM CONTINUUM ESTUÁRIO-OCEANO NA AMAZÔNIA ATLÂNTICA
}

\author{
Rodrigues, A.C.M. ${ }^{1, *} \&$ Martinelli-Lemos, J.M. ${ }^{1}$ \\ ${ }^{1}$ Universidade Federal do Pará (UFPA), Belém, PA. Laboratório de Biologia Pesqueira e Manejo de Recursos \\ Aquáticos, Grupo de Pesquisa em Ecologia de Crustáceos da Amazônia (GPECA). \\ *Autor correspondente: eukarolmelo@gmail.com
}

\begin{abstract}
Levando em consideração a extensa área de abrangência da pluma amazônica no Atlântico adjacente e o importante papel dos Anomura, Axiidea e Gebiidea como indicadores de qualidade ambiental, estudos sobre as larvas destes crustáceos são relevantes para compreender a dinâmica e o ciclo de vida das espécies nesta região. Este trabalho objetivou identificar como as larvas desses crustáceos estão distribuídas e quais fatores ambientais influenciam sua distribuição na Plataforma Continental do Amazonas (PCA). As larvas foram coletadas trimestralmente de julho/13 a janeiro/15, em um transecto perpendicular à zona costeira da Ilha do Marajó, Pará, em 6 pontos de amostragem a 23, 53, 83, 158, 198 e $270 \mathrm{~km}$ de distância da costa (DC), através de arrastos superficiais e oblíquos com rede de plâncton de $200 \mu \mathrm{m}$. Dados de temperatura, salinidade e clorofila-a foram registrados com um perfilador CTD e os dados de vazão obtidos pela Agência Nacional das Águas. Para correlacionar a densidade larval com as variáveis ambientais foi realizado um teste de correlação de Spearman. A variação da densidade larval entre os cruzeiros e pontos de amostragem foi testada com Kruskal-Wallis. Foram encontradas 6 famílias de Anomura (Diogenidae, Paguridae, Porcellanidae, Munididae, Albuneidae e Hippidae), 2 de Gebiidea (Upogebiidae e Laomediidae) e 1 de Axiidea (Callianassidae). A maior densidade foi de Callianassidae (média 19,05 $\pm 61,76$ larvas $/ 100 \mathrm{~m}^{3}$ ), presente em todos os meses e a única família presente em todos os pontos. A densidade de Hippidae variou significativamente com os meses ( $\mathrm{KW}-\mathrm{H}=26,11 ; p=0,0002$ ), com máxima em maio/14 $\left(105,31\right.$ larvas $\left./ 100 \mathrm{~m}^{3}\right)$, estando positivamente correlacionada com a vazão $(R=0,47)$ e teve maior média em $158 \mathrm{~km}$ de DC (KW-H=12,70; $\mathrm{p}=0,02)$. A densidade de Diogenidae e Paguridae correlacionou significativamente com salinidade $(R=0,35 ; R=0,22$; respectivamente) e Porcellanidae com a temperatura $(R=0,33)$, estas três famílias apresentaram maior média de densidade a $83 \mathrm{~km}$ de $\mathrm{DC}(\mathrm{KW}-\mathrm{H}=27,54$; $12,85$ e 24,42; respectivamente, $\mathrm{p}<0,05)$. Munididae estiveram presentes exclusivamente nos pontos 198 e 270 $\mathrm{km}$ de $\mathrm{DC}$, apresentando correlação positiva com a salinidade $(R=0,25)$ e negativa com a temperatura $(R=-0,38)$ e com a clorofila-a $(R=-0,25)$. Estes resultados confirmam a PCA como ambiente diverso e variável quanto à composição e à distribuição larval ao longo de sua extensão, bem como a variação dos fatores ambientais pode alterar o modo de vida das populações de crustáceos.
\end{abstract}

Palavras-chave: Anomuros, ecologia, estuário, meroplâncton, talassinídeos. 